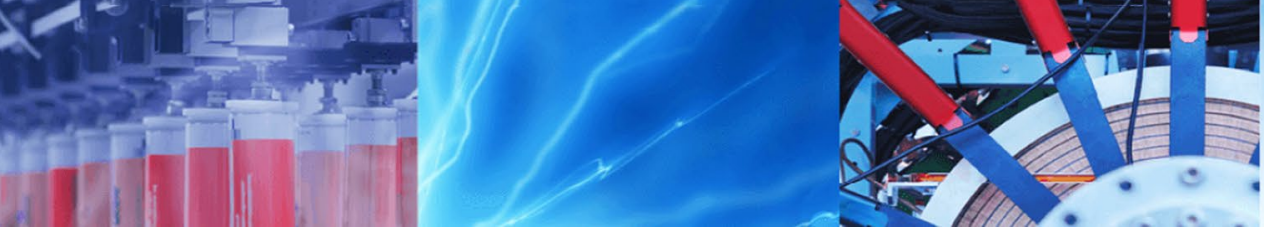

Research Article

\title{
Thermal behaviour of metakaolin-bauxite blends geopolymer: microstructure and mechanical properties
}

\author{
Raphael Belinga Essama Boum ${ }^{1,3} \cdot$ Cyriaque Rodrigue Kaze $^{2} \cdot$ Juvenal Giogetti Deutou Nemaleu$^{1}$ (1) . \\ Viviane Bakaine Djaoyang ${ }^{1}$. Nkwaju Yanou Rachel ${ }^{1}$. Patrick Lemougna Ninla ${ }^{1}$. Francois Mvondo Owono ${ }^{3}$. \\ Elie Kamseu ${ }^{1,4}$
}

Received: 11 March 2020 / Accepted: 23 June 2020 / Published online: 9 July 2020

(c) Springer Nature Switzerland AG 2020

\begin{abstract}
This paper investigates the use of bauxite widely available in northern Cameroon as an additive in the optimization of some properties of metakaolin-based geopolymer. To do this, several geopolymer mixtures were prepared by substituting metakaolin (MK) by bauxite (BA) (from 0 to $50 \%$ ) and partially kept at room temperature $\left(28^{\circ} \mathrm{C}\right.$ ), while others were sintered at 200,800 and $1200^{\circ} \mathrm{C}$. The raw materials and resulting products were characterized using X-ray fluorescence spectrometry (XRF), X-ray diffraction (XRD), Fourier transform infrared spectroscopy (FTIR), densification parameters, mechanical properties as well as microstructural morphologies. The results revealed that the setting time of the geopolymer pastes increased with the bauxite content due to its low dissolution in alkaline medium at room temperature. The mechanical strength of samples decreased from 35.20 to $11.10 \mathrm{MPa}$ at room temperature. At $1200^{\circ} \mathrm{C}$, the higher strengths $(50,98$ and $70 \mathrm{MPa}$ ) were achieved in MKBA10, MKBA20 and MKBA30, respectively. These samples also exhibited dense and compact microstructure partially due to packing particles effect and the nature of bauxite known as refractory material. Thermal shrinkage and relatively high mass losses reflected the decomposition of chemical compounds within the system. Thus, the synthesized materials heated at $1200^{\circ} \mathrm{C}$ could be used as a potential candidate for refractory applications.
\end{abstract}

Keywords Bauxite $\cdot$ Kaolinitic clay $\cdot$ Geopolymers $\cdot$ Mechanical properties $\cdot$ Thermal shrinkage $\cdot$ Microstructure

\section{Introduction}

Geopolymer binders are new cementitious materials that are formed from a mixture of an aluminosilicate with alkaline or acid solution cured at room temperature. Their structure consists of repeating units of $\mathrm{Si}-\mathrm{O}-\mathrm{Al}$ bindings [1]. Compared to Portland cement, geopolymer is more ecological friendly as they require less energy for their synthesis [2]. It is produced from natural aluminosilicates such as kaolin and volcanic ash $[3,4]$ or industrial waste products like fly ash and slag [5, 6]. Owing to their high mechanical strength, geopolymer materials can be applied in the civil engineering, construction and off-shore sectors, as they are highly resistant to most chemical aggressions that are real plagues to conventional concretes [7-12]. In literature, metakaolin is widely used as a solid precursor for geopolymer binder. Several authors investigated the thermal behaviour of metakaolin-based geopolymer for high-temperature applications [13-16]. In addition, it has been demonstrated that the thermal behaviour of metakaolin blends with silica or alumina improves the mechanical strength. For example, Kamseu et al. [17] showed that the

Cyriaque Rodrigue Kaze, kazerodrigue@gmail.com; $\bowtie$ Juvenal Giogetti Deutou Nemaleu, giogetti@live.fr|' ${ }^{1}$ Local Material Promotion Authority (MIPROMALO), P.O. Box, 2396, Yaoundé, Cameroun. ${ }^{2}$ Laboratory of Applied Inorganic Chemistry, Faculty of Science, University of Yaoundé I, P.O. Box 812, Yaoundé, Cameroon. ${ }^{3}$ Department of Earth Science, University of Douala, P.O. Box. 24157, Douala, Cameroon. ${ }^{4}$ Dipartimento Di Ingegneria Dei Materiali E Dell'Ambiente, Università Di Modena E Reggio Emilia, Via Vignolese 905 , 41100 Modena, Italy. 
addition of quartz or fine alumina to metakaolin improved the thermal stability of the resulting products for hightemperature applications $\left(1200^{\circ} \mathrm{C}\right)$. Rashad and Ouda [18] partially substituted metakaolin with nanosilica (at ratios of 0.5 to $4 \%$ ) and heated the 28 -day resulting products up to $1200^{\circ} \mathrm{C}$. They found that the incorporation of $0.5 \%$ of nanosilica enhanced the mechanical strength and fire resistance of metakaolin-based geopolymer. Martin et al. [19] in their work replaced fly ash by $15 \%$ of bauxite. After heating between 200 and $1000{ }^{\circ} \mathrm{C}$, the sample containing bauxite additive presented a better heat resistance compared to that used as a reference. Those authors concluded that the characteristics of the thermal behaviour of geopolymer-based binders depend on physical and mineralogical compositions of solid precursors as well as the hardeners used. However, the final characteristics of geopolymer binder exposed to high temperatures remained high compared with ordinary Portland cement. The current alumina source used to improve the stability of geopolymer at high temperatures up to now in the literature was red mud from Bayer process [20-22]. Recently, Tiffo et al. [23] investigated the thermal properties of metakaolin-based geopolymer altered by $0-30 \mathrm{wt} \%$ of two types of aluminium sources (amorphous aluminium hydroxide $\left(\mathrm{Al}(\mathrm{OH})_{3}\right)$ and semi-crystalline aluminium oxy-hydroxide $(\gamma-\mathrm{AlO}(\mathrm{OH}))$. The authors reported that the partial replacement of amorphous aluminium hydroxide or aluminium oxy-hydroxide in the synthesis of kaolin-based geopolymers allows improvement in both compressive strength and thermal stability of heated specimens.

This project deals with the use of alumina source from bauxite as an additive in MK-geopolymer synthesis and performance evaluation of the end products. The use of alumina from bauxite would be expected to improve the stability of the synthesized products at high temperatures. Therefore, highly pure grade alumina contained in the bauxite during the heating process would directly influence the thermal expansion, the phase composition and the morphology of the geopolymer products.

Bauxite widely available in Minim Martap (Cameroon) would be used to produce alumina source. Metakaolin was partially replaced by $10,20,30,40$ and 50 wt $\%$ by mass. Part of resulting products were kept at room temperature $\left(25^{\circ} \mathrm{C}\right)$, and other specimens were sintered at $200^{\circ} \mathrm{C}, 800$ and $1200^{\circ} \mathrm{C}$ in order to investigate the fire resistance. This research paper could provide a basis for the design of refractory geopolymer materials based on metakaolin-bauxite blends, and it is of great significance for its popularization and application. The heated and unheated products were studied by means of setting time, compressive strength, water absorption, thermal shrinkage, porosity and density. The microstructure and structure were evaluated using the scanning electron microscopy
(SEM), Fourier transform infrared (FTIR) and X-ray diffraction (XRD) analyses.

\section{Experimental procedures}

\subsection{Materials}

The kaolin clay used in this study was collected from Mvan neighbourhood in Yaoundé town (Cameroon). Bauxite used as alumina source was collected from Mini Martap locality situated in the north region of Cameroon. The chemical composition of both raw materials is reported in Table 1. After harvesting, both materials were dried, milled and sieved using a mesh of $80 \mu \mathrm{m}$. The resulting fine kaolin powder obtained after sieving was heated at $700{ }^{\circ} \mathrm{C}$ to produce metakaolin as a main solid precursor for the present work. This temperature was mainly used in the literature as the best calcination temperature for the dehydroxylation of clayey materials [13].

The alkaline solution was a mixture of an aqueous solution of sodium hydroxide $(10 \mathrm{M})$ mixed with commercial sodium silicate in a ratio of 2 , to obtain a modulus silicate $\left(\mathrm{Ms}=\mathrm{SiO}_{2} / \mathrm{Na}_{2} \mathrm{O}\right)$ of 1.5 and $\mathrm{H}_{2} \mathrm{O} / \mathrm{Na}_{2} \mathrm{O}$ ratio of 10 and then stored at room temperature for $24 \mathrm{~h}$ (h) before using. The sodium silicate solution used in this study was supplied by Ingessil s.r.l. Verona (Italy), and its chemical composition was $14.37 \mathrm{wt} \% \mathrm{Na}_{2} \mathrm{O}, 29.54 \mathrm{wt} \% \mathrm{SiO}_{2}, 56.09 \mathrm{wt} \% \mathrm{H}_{2} \mathrm{O}$. Sodium hydroxide solution (10 M) was prepared by dissolving $\mathrm{NaOH}$ pellets (Sigma-Aldrich, Italy, purity $\geq 98 \%$ ) in distilled water.

\subsection{Metakaolin-bauxite-based geopolymer processing}

To prepare the MK-bauxite geopolymer binders, metakaolin was firstly hand-mixed with bauxite in the range of 10 , $20,30,40$ and $50 \mathrm{wt} \%$ for $5 \mathrm{~min}$. Secondly, the alkaline solution was added to the mixture in a constant ratio of 0.8 for each formulation. The viscous pastes were poured into

Table 1 Chemical composition of raw materials

\begin{tabular}{lll}
\hline Oxide & Metakaolin (MK) & Bauxite (BA) \\
\hline $\mathrm{SiO}_{2}$ & 40 & 31.5 \\
$\mathrm{Fe}_{2} \mathrm{O}_{3}$ & 3.44 & 6.52 \\
$\mathrm{Al}_{2} \mathrm{O}_{3}$ & 48.10 & 57.4 \\
$\mathrm{TiO}_{2}$ & 1.00 & 3.50 \\
$\mathrm{CaO}$ & 0.90 & 0.85 \\
$\mathrm{~K}_{2} \mathrm{O}$ & 0.72 & $/$ \\
$\mathrm{Na}_{2} \mathrm{O}$ & 0.44 & $/$ \\
$\mathrm{LOI}$ & 5.4 & 0.23 \\
\hline
\end{tabular}


cylindrical moulds and covered with thin plastic film to avoid carbonatation. After $24 \mathrm{~h}$, the resulting samples were demoulded and divided into two series. The first samples aged 28 days were kept at room temperature $\left(28^{\circ} \mathrm{C}\right)$ until the mechanical test was carried out at 28 days. The second series was thermally heated at high temperatures of 200,800 and $1200^{\circ} \mathrm{C}$ after 28 days. The geopolymer specimens were labelled MKB0, MKB10, MKB20, MKB30, MKB40 and MKB50, where $0,10,20,30,40$ and 50 represent the amount of bauxite in the whole system.

\subsection{Characterization methods}

The chemical composition of kaolin clay and bauxite was carried out using X-ray Fluorescence Spectrometer Bruker S8 Tiger. Prior to the analysis, each sample powder was mixed with lithium borated salt and vitrified within a $\mathrm{Pt}$ crucible at $1060^{\circ} \mathrm{C}$. The loss on ignition at $1050^{\circ} \mathrm{C}$ was considered to perform the calculation of the final chemical compositions.

$\mathrm{X}$-ray diffraction (XRD) analysis is known as a technique used to define the mineralogical composition of a material. The mineralogical composition of the bauxite, metakaolin and different geopolymer samples was identified using X-ray diffraction (XRD) with a reflection Brucker AXS D8 Advance Debye-Scherrer-type diffractometer. Measurements were performed on powders resulting from starting materials and consolidated products, using a step scan mode in the range $5.02^{\circ} \leq 2 \theta \leq 80^{\circ}$, with a counting time of $10.1 \mathrm{~s}$ per $0.02^{\circ}$ step $(2 \theta)$. Crystalline phases were identified by comparison the peaks with Powder Diffraction Files (PDF standards) from the International Center for Crystallography Data (ICCD). In all cases, the Ka1 wavelength of copper $(\lambda=1.5418 \AA ̊)$ was used.

Attenuated total reflectance and Fourier transform infrared spectroscopy (ATR-FTIR) technique was used to determine the main characteristic chemical groups in the raw, calcined and consolidated materials. For this study, a Nicolet 6700 apparatus from Thermo Scientific has been used. For the measurements, each sample was placed over a reflective crystal medium where light was passed through. The reaction cell was then fixed onto the diamond ATR crystal, and FTIR spectra data were recorded over the range of 4000 to $400 \mathrm{~cm}^{-1}$ at a resolution of $2 \mathrm{~cm}^{-1}$ with 32 scans.

Simultaneous differential thermal analysis and thermogravimetric analysis (DSC/TG) was performed on the two samples, using a Netzsch STA 429 CD unit in an air atmosphere. The analysis was carried out on ground powders at a heating rate of $20 \mathrm{~K} / \mathrm{min}$ in platinum rhodium crucibles using calcined alumina as a reference.

The compressive strength of the samples was measured with an Instron 1195 Compression machine with a displacement of $5 \mathrm{~mm} / \mathrm{min}$. The results shown are an average of four replicate specimens following Eq. 1:

$\delta=\frac{4 \times 1000 \times F}{\pi \times D \times D}$

where $\delta$ is the compressive strength (MPa), $F$ the force $(\mathrm{kN})$ and $D$ the diameter $(\mathrm{m})$.

The initial and final setting times were measured on the fresh pastes of metakaolin-bauxite geopolymers using the Vicat apparatus. The initial setting was verified at $10 \mathrm{~min}$ just after the preparation of the paste and every minute when the first resistance to Vicat was detected. This was done in the laboratory with $54 \%$ of relative humidity and temperature of $21 \pm 2{ }^{\circ} \mathrm{C}$. The test was performed according to the EN 196-3 Standard. The needle used was $1.00 \pm 0.005 \mathrm{~mm}$ in diameter.

Pieces from the mechanical testing were polished, goldcoated and dried for microstructural observations using a JEOL IT300LV Scanning Electron Microscope (SEM) coupled with energy-dispersive X-ray spectroscopy (EDX) with an acceleration voltage of $10.0 \mathrm{kV}$.

The water absorption analysis was carried out by immersing the specimen with and without bauxite cured at room temperature and those heated at high temperatures in water at ambient temperature for $24 \mathrm{~h}$ and comparing the humid weight $(\mathrm{mh})$ to the dry weight $(\mathrm{md})$ according to Eq. 2:

$\mathrm{Wa}=\frac{(\mathrm{mh}-\mathrm{md})}{\mathrm{md}} \times 100$

Measurements of thermal linear shrinkage were made with a calliper that was used to determine the length variations of 28-day-old and processed specimens at $1200^{\circ} \mathrm{C}$. For each series, the length before and after heating was determined. By designating, respectively, with RLc the linear thermal shrinkage, $L i$ the initial length and by $L f$ the final length of the specimens before and after the heat treatment, the linear shrinkage of the firing is therefore given by the following relationship (3):

$\mathrm{RLC}=[(\mathrm{Li}-\mathrm{Lf}) / \mathrm{Li}] \times 100$

\section{Results and discussion}

\subsection{Raw materials}

Figure 1a displays the mineralogical phases of bauxite such as gibbsite $(\mathrm{G})\left(\mathrm{Al}(\mathrm{OH})_{3}\right.$, PDF cards \#33-180) quartz (Q) $\left(\mathrm{SiO}_{2}, \mathrm{PDF}\right.$ cards \#46-1045), corundum (Cn) (-a- $\mathrm{Al}_{2} \mathrm{O}_{3}$, PDF cards \#10-173), boehmite (Bo) (- $\gamma-\mathrm{AlO}(\mathrm{OH}), \mathrm{PDF}$ cards \#21-1307), haematite (He) (- $a-\mathrm{Fe}_{2} \mathrm{O}_{3}$, PDF cards \#13-534), 



Fig. 2 Differential thermal analysis (DTA) and thermogravimetric (TG) of raw materials: a kaolin and $\mathbf{b}$ bauxite

Fig. 1 XRD analysis of raw materials: $\mathbf{a}$ bauxite and $\mathbf{b}$ metakaolin

diaspore (Di) (- $\beta-\mathrm{AlO}(\mathrm{OH})$, PDF cards \#5-355) and goethite (Go) (- $a$ - $\mathrm{FeO}(\mathrm{OH})$, PDF cards \#29-713). Major phases such as gibbsite, boehmite, diaspore, quartz and haematite were also reported by the findings of Cardenia et al. [24], Peng et al. [25] as well as Hertel et al. [26, 27]. The major phases contained in metakaolin are quartz $(\mathrm{Q})\left(\mathrm{SiO}_{2}, \mathrm{PDF}\right.$ cards \#46-1045) muscovite (Mu) $\left(\mathrm{KAl}_{2}\left(\mathrm{AlSi}_{3} \mathrm{O}_{10}\right)(\mathrm{F}, \mathrm{OH})_{2}\right.$, PDF cards \#06-263) and haematite (He) $\left(-\mathrm{a}-\mathrm{Fe}_{2} \mathrm{O}_{3}\right.$, PDF cards \#13-534) (Fig. 1b).

Figure 2 presents the performed differential thermal analysis (DTA) and thermogravimetric analysis (TG) of various raw materials used in the study. As shown in Fig. 2a, there were two endothermic peaks $\left(142\right.$ and $\left.565^{\circ} \mathrm{C}\right)$. At $565^{\circ} \mathrm{C}$, this phenomenon was accompanied by a significant weight loss of $10 \%$. The latter corresponds to loss of chemical water molecules including kaolinite dihydroxylation and the formation of the metakaolin [12]. With the increase in sintering temperature, a sharp exothermic peak appeared around $998^{\circ} \mathrm{C}$. This is linked to both spinel crystallization and the acicular mullite crystals into the samples $[28,29]$.

The total mass loss of the bauxite sample is about $27 \%$. Three endothermic peaks were clearly observed in the DTA curves (Fig. 2b). The first event occurred at $125^{\circ} \mathrm{C}$, linked to the loss of absorbed humidity in the raw materials. At $340^{\circ} \mathrm{C}$, there were sharp endothermic peaks combined with a significant mass loss of $25 \%$, thus considering the decomposition of gibbsite. The third event was at $545^{\circ} \mathrm{C}$, due to the transformation of boehmite to alpha-alumina [29]

The FTIR spectra of metakaolin and bauxite used as solid precursors are depicted in Fig. 3a, b, respectively. The band appearing at $1632 \mathrm{~cm}^{-1}$ in metakaolin spectra (Fig. 3a) is related to the bending vibration of $\mathrm{O}-\mathrm{H}$ bond belonging to physico-absorbed water molecules. The second band with high intensity located at $1077 \mathrm{~cm}^{-1}$ is attributed to the vibration modes of $\mathrm{Si}-\mathrm{O}-\mathrm{Al}$ bonds. The absorption band around $871 \mathrm{~cm}^{-1}$ is attributed to the stretching vibration of $\mathrm{Al}(\mathrm{VI})-\mathrm{OH}$ and $\mathrm{Al}(\mathrm{VI})-\mathrm{O}$ bonds. The last absorption bands situated at 790 and $690 \mathrm{~cm}^{-1}$ are assigned to stretching and bending vibrations of $\mathrm{Si}-\mathrm{O}-\mathrm{Al}(\mathrm{IV})$ and $\mathrm{Si}-\mathrm{O}-\mathrm{Al}(\mathrm{VI})$ bonds [3, 30], while the FTIR spectra of bauxite (Fig. 3b) exhibited the absorption bands at 3368, 3442, 3523 and 



Fig. 3 FT-IR spectra of solid precursor: $\mathbf{a}$ metakaolin and $\mathbf{b}$ bauxite

$3617 \mathrm{~cm}^{-1}$ that are linked to the stretching frequencies of $\mathrm{O}-\mathrm{H}$ bonds of gibbsite which is the main mineral of bauxite confirmed by XRD and TG analyses. However, the bands located between 913 and $1014 \mathrm{~cm}^{-1}$ correspond to vibration modes of $\mathrm{O}-\mathrm{H}$ groups of water molecules [31]. The last bands 731,651 and $447 \mathrm{~cm}^{-1}$ are linked to the bending vibrations of $\mathrm{O}-\mathrm{H}$ bonds of gibbsite [32].

\subsection{Setting times}

The results of setting time of metakaolin-bauxite geopolymer binders are reported in Table 2. From this, it is noticed that the setting time increased with the addition of bauxite from 0 to $50 \mathrm{wt} \%$. The values of setting time were $2 \mathrm{~h} 30 \mathrm{~min}, 2 \mathrm{~h} 52 \mathrm{~min}, 3 \mathrm{~h} 00 \mathrm{~min}, 3 \mathrm{~h} 07 \mathrm{~min}, 3 \mathrm{~h}$ $28 \mathrm{~min}$ and $4 \mathrm{~h} 00$, respectively, for MKB0, MKB10, MKB20, MKB30, MKB40 and MKB50. The significant increase in setting time from MKB10 to MKB50 sample could be due to the low dissolution of bauxite in alkaline medium at room temperature. Adding raw bauxite in geopolymer matrix does not allow the availability of aluminium species required to polymerize with silica ones leading to long
Table 2 Setting time behaviour of the metakaolin-bauxite geopolymer binders
Geopolymer Setting times

setting times recorded in different specimens. Thus, this could affect the alumina content consequently delaying the geopolymer process by increasing the setting time. This trend is in line with the findings of Duxson et al. [33] on metakaolin-based geopolymer synthesis which shows that the $\mathrm{Si} / \mathrm{Al}$ ratio less than 2 induces a long setting time. From the findings of Djobo et al. [34], they used raw bauxite as an additive (0-30 wt\%) in the volcanic ash-based geopolymer and they noticed reduction in setting times from 415 to $275 \mathrm{~min}$. In their work, the use of bauxite improved the alumina content in volcanic ash, whereas in the given work metakaolin is richer in alumina species compared to volcanic ash (less than $20 \%$ ).

\subsection{Phases evolution}

\subsubsection{FTIR}

The FTIR spectra of geopolymer MKBA0, MKBA10, MKBA20 and MKBA50 samples (cured at room temperature) describing the structural network are plotted in Fig. 4. The broad absorption bands located at intervals 3386-3395 and $1650-1653 \mathrm{~cm}^{-1}$ are attributed to $\mathrm{O}-\mathrm{H}$ stretching and $\mathrm{O}-\mathrm{H}$ bending of water molecules, while the bands

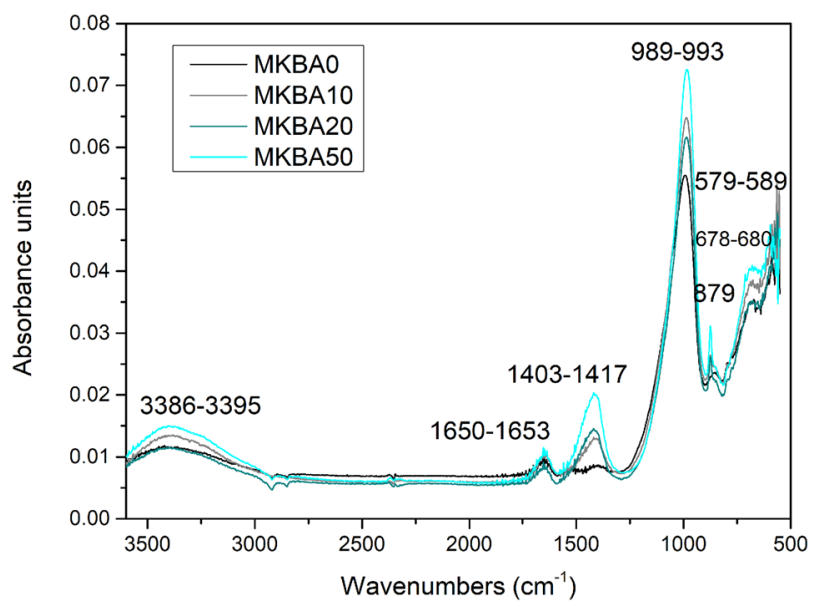

Fig. 4 FT-IR spectra of the geopolymer specimens 
between $1403-1417 \mathrm{~cm}^{-1}$ correspond to stretching vibration of $\mathrm{C}-\mathrm{O}$ provided by the reaction of unreactive $\mathrm{Na}^{+}$ ions with $\mathrm{CO}_{2}$ from atmosphere [35]. This band rises with an increase in bauxite from 10 to $50 \mathrm{wt} \%$ indicating the lower dissolution of bauxite in alkaline medium at room temperature; this is related to the important amount of unfixed $\mathrm{Na}^{+}$ions into geopolymer network leading to efflorescence phenomenon. The broad band observed on spectra of MK at $1077 \mathrm{~cm}^{-1}$ shifted to $989 \mathrm{~cm}^{-1}$ after alkaline activation. This displacement is due to the formation of geopolymer network binder [35]. The main bands related to geopolymer footprint formation situated between 989 and $993 \mathrm{~cm}^{-1}$ are assigned to $\mathrm{Si}-\mathrm{O}-\mathrm{Al}$ stretching vibrations [36-38]. This band becomes broader with the incorporation of bauxite (from 0 to $40 \mathrm{wt} \%$ ), suggesting the possible insertion of additional aluminium cations resulting in high extension of geopolymer network. The absorption bands located around $879 \mathrm{~cm}^{-1}$ correspond to distorted Al (VI) sites or to Al sites with different coordination [12]. The last bands that appeared in the ranges of $678-680 \mathrm{~cm}^{-1}$ and
$579-589 \mathrm{~cm}^{-1}$ are attributed to symmetrical stretching vibrations of $\mathrm{Si}-\mathrm{O}-\mathrm{Si}, \mathrm{Si}-\mathrm{O}-\mathrm{Al}$ and $\mathrm{Si}-\mathrm{O}$, respectively [39].

\subsubsection{XRD analysis}

The X-ray patterns of geopolymer mixed with/without bauxite are presented in Fig. 5a-d. It is observed that some crystalline phases (muscovite, quartz and haematite) existing in metakaolin diffractogram used as a starting material are still present after geopolymerization process on sample without additive (bauxite). The presence of these phases indicates the non-purity of raw material used for the synthesis. Similar observations were found by some researchers on investigation of geopolymer properties where metakaolin was obtained from calcined kaolin $[38,40,41]$. These authors stated that the unreacted mineral phases during geopolymerization reaction seem to behave as aggregates or fillers, suggesting the reinforcement of geopolymer matrix. However, with the addition of 10 and $20 w t \%$ of bauxite (Fig. 5b, c, respectively),
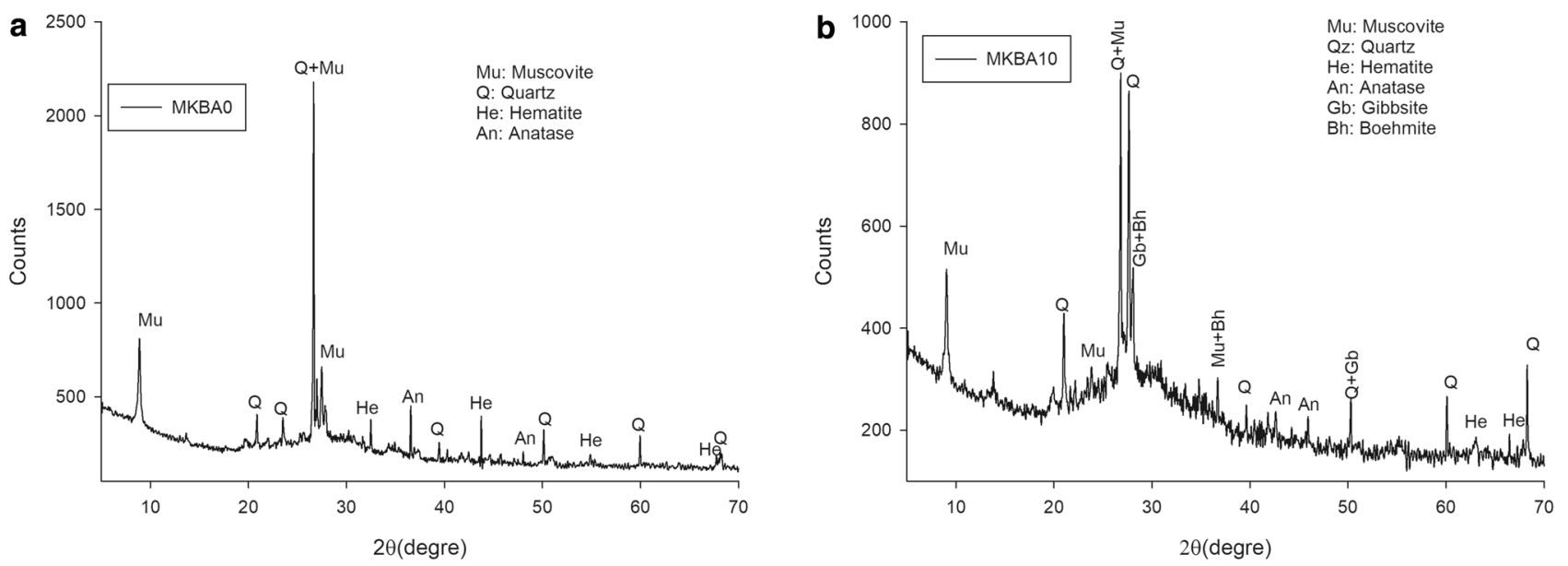

C
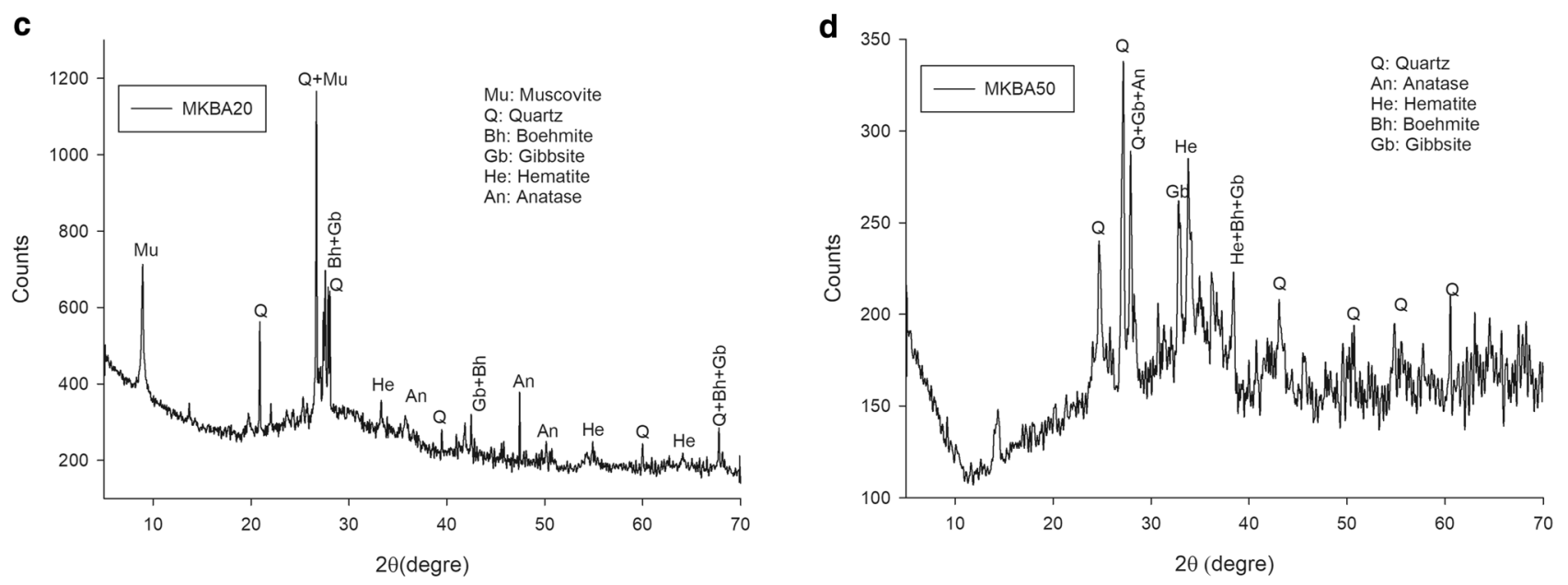

Fig. 5 XRD analysis of the geopolymer samples with bauxite addition: a 0 wt $\%$, b 10 wt $\%$, c 20 wt $\%$ and d 50 wt $\%$ 
the hump located between $20^{\circ}$ and $40^{\circ}$ (2theta range) observed on the diffractograms of MKBA10 and MKBA20 geopolymer samples is more pronounced compared to that of MKBAO (Fig. 5a). This trend might suggest the weak partial dissolution or participation of bauxite during the geopolymerization reaction and thus slightly contributed to the extension of amorphous phase. Nevertheless, this hump was completely destroyed with the addition of 50 wt\% of bauxite (Fig. 5d). To confirm this results, further analysis using Rietveld refinement method is prospected to exactly quantify the amorphous content of each of the end products.

\subsection{Mechanical properties}

The compressive strengths of metakaolin-based geopolymers containing $0,10,20,30,40$ and $50 \%$ of bauxite (additive) cured at room temperature $\left(28^{\circ} \mathrm{C}\right.$ without exposure) and those exposed at higher temperatures $(200,800$ and $1200^{\circ} \mathrm{C}$ ) are depicted in Fig. 6 . From Fig. 6 , it is noticed that at room temperature the compressive strength significantly decreased from 35.20 to $11.10 \mathrm{MPa}$ (Fig. 6), with an increasing bauxite addition (from 0 to $50 \mathrm{wt} \%$ ). This could be due to the low dissolution of bauxite in alkaline solution affecting the polysialate geopolymer binder phase, resulting in low strength. In addition, the substitution of metakaolin as a main solid precursor by bauxite from 0 to $50 \mathrm{wt} \%$ altered the amount of reactive amorphous phase coming from metakaolin although the resulting products appeared amorphous according to XRD and SEM analyses. When the thermal treatment was applied, the reverse effect was observed between 200 and $1200^{\circ} \mathrm{C}$. In samples containing 10 and $20 \mathrm{wt} \%$ of bauxite with the evolution of thermal treatment temperature from 200 to $800{ }^{\circ} \mathrm{C}$,

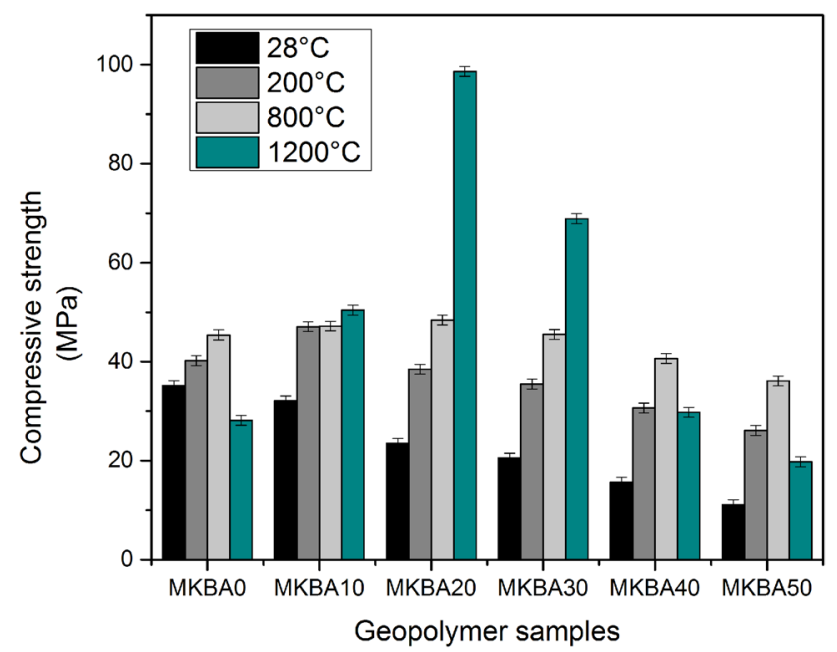

Fig. 6 Compressive strength behaviour of the geopolymer samples boehmite and gibbsite as main mineral phases contained in bauxite at elevated temperatures would allow the formation of aluminates contributing to densify the geopolymer network, justifying the high strength achieved. This increase could be due to the packing particles effect within the geopolymer matrix. The high strengths $(50,98$ and $70 \mathrm{MPa}$ ) achieved on MKBA10, MKBA20 and MKBA30 samples at $1200^{\circ} \mathrm{C}$ are likely due to the presence of some mullite crystals leading to strengthening agent. Similar trend was observed by Tiffo et al. [23] at $1200^{\circ} \mathrm{C}$. They declared that the improvement in compactness of refractory geopolymer specimens was related to the formation of stable crystalline phases. Comparable tendency focused on thermal treatment of metakaolin-containing nanosilica was also obtained by Rashaad et al. [18].

\subsection{Microstructure}

Figures 7 and 8 present the micrographs of MKBAO and MKBA20 specimens cured at room temperature $\left(28^{\circ} \mathrm{C}\right)$ and their counterparts heated at $1200{ }^{\circ} \mathrm{C}$. The SEM images exhibited the morphologic changes that occurred within geopolymer structure before and after exposure to $1200^{\circ} \mathrm{C}$. The micrographs of MKBAO (Fig. 7a) cured at room temperature appeared homogeneous, compact and dense, justifying the highest strength achieved. The MKBA20 sample (containing $20 \mathrm{wt} \%$ of bauxite) at same temperature exhibited almost homogeneous microstructure, with some cracks across its surface (Fig. 7b). The cracks observed on MKBA20 could be due to the release of water molecules occupying the cavities which became empty, creating open voids and cracks [31]. The micrographs of samples heated at $1200^{\circ} \mathrm{C}$ are reported in Fig. 8 . One can observe that the geopolymer MKBA0 (Fig. 8a) without additive appears more porous with a spongelike structure as compared to that of MKBA20 which is still compact and dense (Fig. 8b). The difference observed could be due to the transformation of unreacted alumina in bauxite to mullite which contributed to the densification of geopolymer matrix. The appearance of voids and pores observed on different samples is related to the departure of water molecules belonging to geopolymer network (sodium aluminosilicate hydrate N-A-S-H) resulting in decreasing compressive strength. The presence of these voids on micrographs of heated samples is in accordance with the trend of mechanical performances observed on samples heated at $1200^{\circ} \mathrm{C}$. It is also noticed that some unreacted particles observed on both samples cured at room temperature disappeared after being exposed at $1200^{\circ} \mathrm{C}$ indicating the formation of denser amorphous aluminosilicate binder phase with a homogeneous surface. The characteristics of strength achieved in samples heated at $1200^{\circ} \mathrm{C}$ in the study are in agreement with previous 

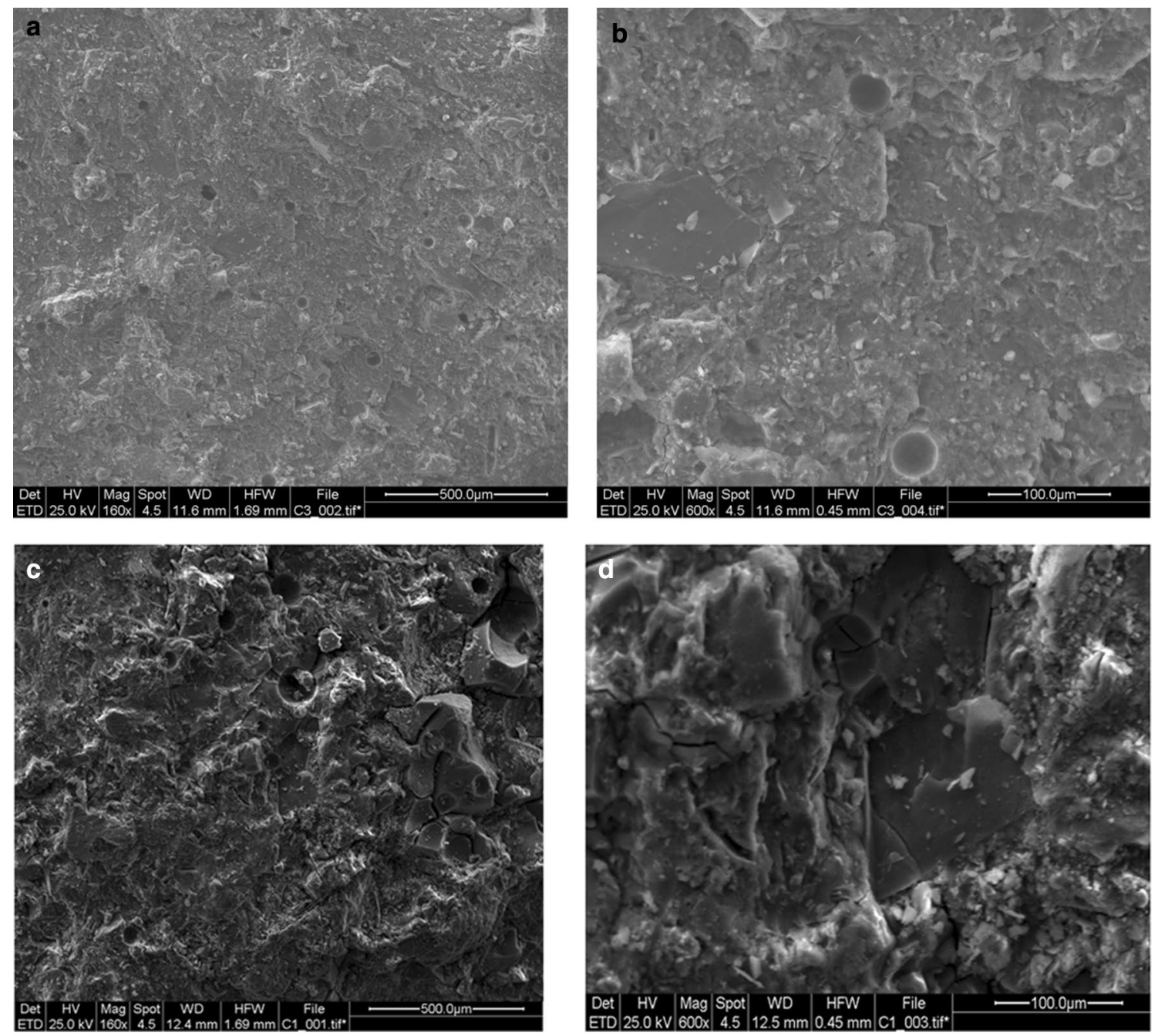

Fig. 7 Micrographs of the geopolymer samples cured at room temperature, $25^{\circ} \mathrm{C}$ : a MKBA0 and $\mathbf{b}$ MKBA20

works in the literature, where the authors improved the thermal performances of fly ash geopolymer by adding microsilica at higher temperatures [18].

\subsection{EDS analysis}

The EDS spectrum (Fig. 9) was obtained from MKBAO and MKBA20 samples heated at $1200^{\circ} \mathrm{C}$. From Fig. 9 , it is noticed that the geopolymer matrices comprise the $\mathrm{Si}, \mathrm{Al}$, $\mathrm{Fe}, \mathrm{Na}, \mathrm{K}$ and $\mathrm{O}$ as major elements with the trace of $\mathrm{Ti}$. The major elements above-mentioned confirm the formation of sodium aluminosilicate binder phase (N-A-S-H) responsible for the strength development gained in this project.

\subsection{Water absorption}

The water absorption values of metakaolin-based geopolymer products are presented in Fig. 10. The trend of water absorption is in line with the observation of mechanical properties. For the samples cured at room temperature containing 0,10 and $20 \mathrm{wt} \%$ of additive (bauxite), it is noted that a decrease in water absorption from 12.30 to $8.50 \%$ suggests the filling of pore network or packing particles effect during the geopolymerization by bauxite. However, with above $20 \mathrm{wt} \%$ of bauxite added, a slight increase in water absorption from 9 to $15 \%$ was observed. This could be due to the retention of important amount of water by the free bauxite which was not involved in the geopolymerization reaction when the samples are immersed. Similar trend was observed on samples exposed at higher temperatures. The values were $15-18 \%, 16-19 \%$ and $9.3-12 \%$, respectively, for MKBA30, MKBA40 and MKBA50. On the other hand, the increase in water absorption in all geopolymer formulations with an increase in heating temperature from 25 to $800^{\circ} \mathrm{C}$ is due to the appearance of 

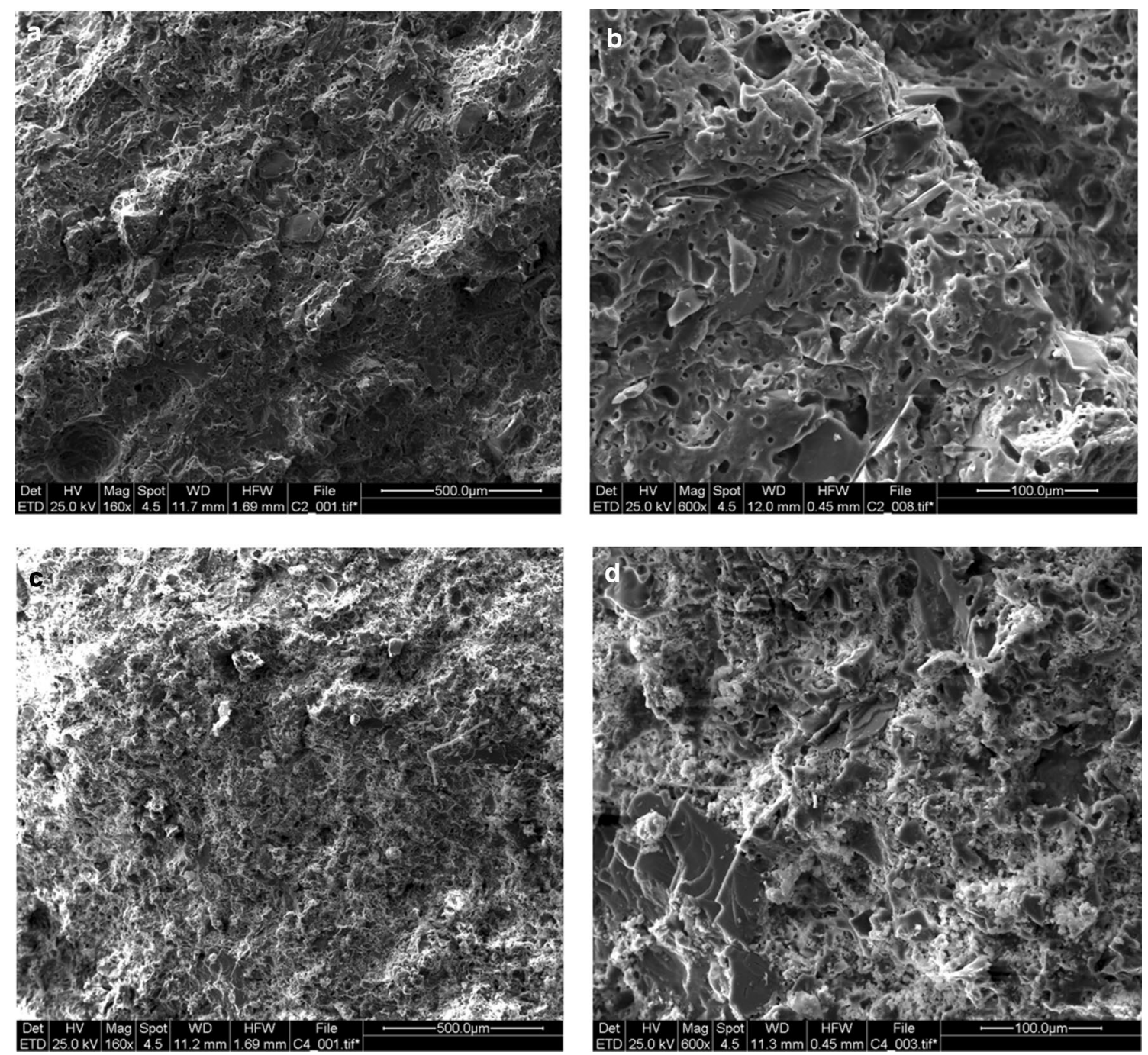

Fig. 8 Micrographs of the geopolymer samples sintered at $1200^{\circ} \mathrm{C}: \mathbf{a}$ MKBA0 and $\mathbf{b}$ MKBA20

pores and cracks resulting in microstructural degradation leading to the water departure out of geopolymer network, which allowed the retention of water. These values were $12-17 \%, 10-15 \%, 9-13 \%, 9-14 \%, 12-17 \%$ and $14-19 \%$, respectively, for MKBA0, MKBA10, MKBA20, MKBA30, MKBA40 and MKBA50 specimens. The low values of water absorption $(9.3,7.1,6.0,6.3,9.2$ and $11.30 \%$, respectively, of MKBA0, MKBA10, MKBA20, MKBA30, MKBA40 and MKBA50) recorded on samples heated at $1200^{\circ} \mathrm{C}$ are likely due to the formation of vitreous phase from quartz and bauxite in the whole system contributing to reinforce or densify the microstructure. So, at this temperature the formation of mullite from bauxite could be expected. Similar observations were reported by the findings of Deutou et al. [28], where the authors used kyanite to improve the crystallization and densification of the high-strength mullite matrix.

\subsection{Thermal shrinkage}

Figure 11 shows the variations in thermal shrinkage of geopolymer samples sintered at $1200^{\circ} \mathrm{C}$. From this figure, the maximum shrinkage limits $(15,20$ and $21.5 \%)$ are obtained for the MKBAO, MKB10 and MKB20 formulations, respectively. The lowest thermal shrinkage values (10.75 and 11.25) are obtained from MKB30 and MKB50 samples. The withdrawal reflects the physico-chemical transformations that occurred within the material subjected to heat treatment. Thus, during the heat treatment of geopolymers, water removal (hygroscopic and structural) or fusion of species was observed within the matrix. The decrease in thermal shrinkage is related to the bauxite content (0-50\%). In fact, at this sintering temperature $\left(1200^{\circ} \mathrm{C}\right)$, a liquid phase resulting from earlier transformation of metakaolin reacted with the alumina coming from bauxite 

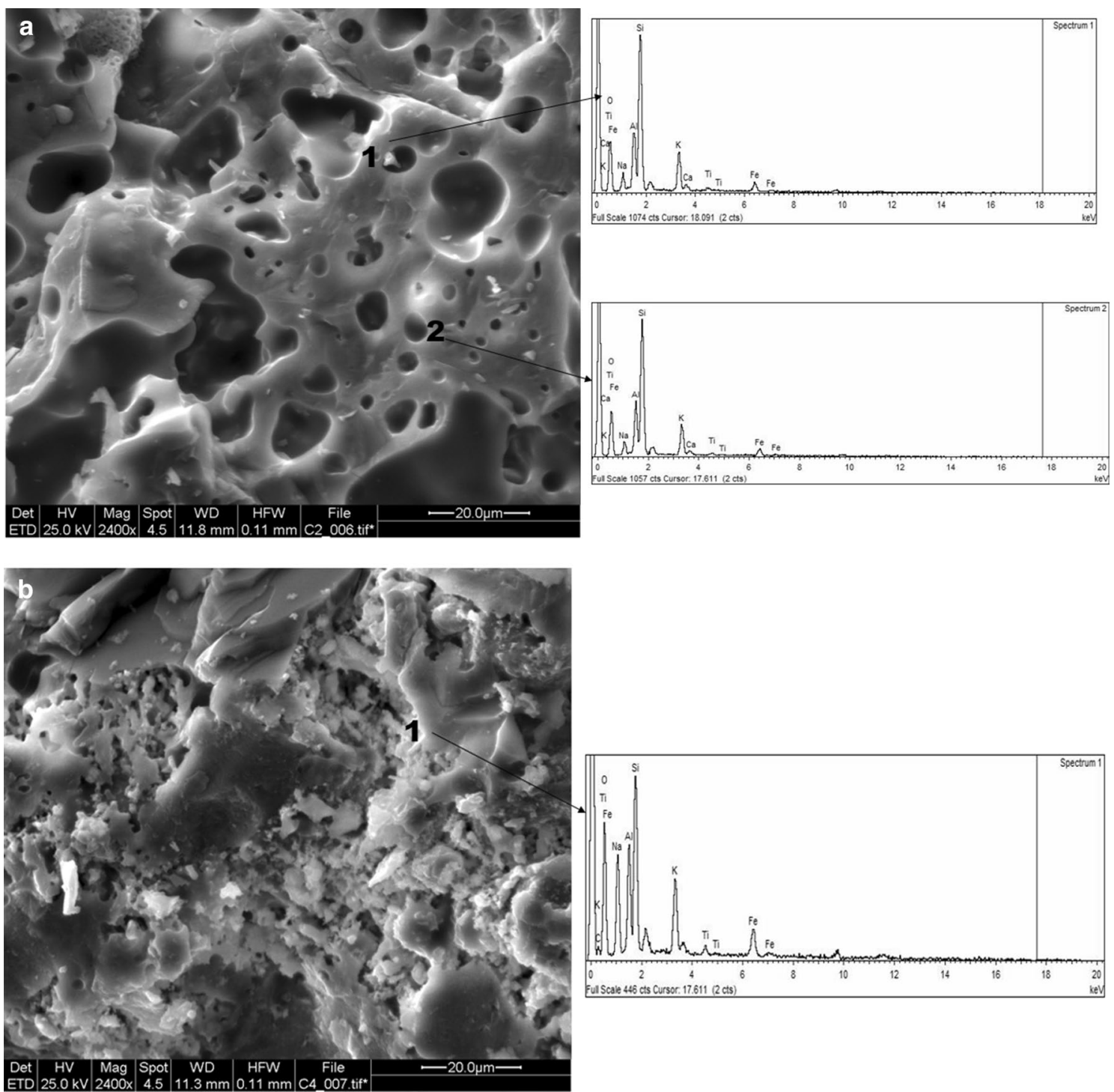

Fig. 9 SEM-EDS of the metakaolin-bauxite geopolymer binders sintered at $1200^{\circ} \mathrm{C}: \mathbf{a}$ MKBA0 and $\mathbf{b}$ MKBA20

to produce the additional mullite crystals in the matrices. Those transformation favoured the densification process in the specimens and consequently in line with the trend of water absorption rate (Fig. 10). The elaborated geopolymers behave like ceramics with regard to their shrinkage which stands at relatively high sintering temperatures as compared to the literature [20].

\section{Conclusion}

This study aimed to design geopolymer from metakaolin altered by $0,10,20,30,40$ and $50 \%$ of bauxite. The setting time was evaluated on fresh pastes. Compressive strength, thermal shrinkage, water absorption and microstructure of unheated and heated samples were well investigated. The following conclusions can be summarized.

1. The increase of bauxite from 0 to $50 \%$ allowed the long setting time, justified by their lower dissolution at room temperature;

2. At room temperature, the addition of bauxite above 20 wt $\%$ negatively affected the mechanical strength evolution, whereas the reverse trend was observed on samples heated at $1200^{\circ} \mathrm{C}$ due to the possible formation of some crystals of mullite;

3. The well-densified matrices of samples MKBA10, MKBA20 and MKBA30 observed could be due to the transformation of unreacted alumina in bauxite to mullite which contributed to the densification of geopolymer matrix;

\section{SN Applied Sciences}




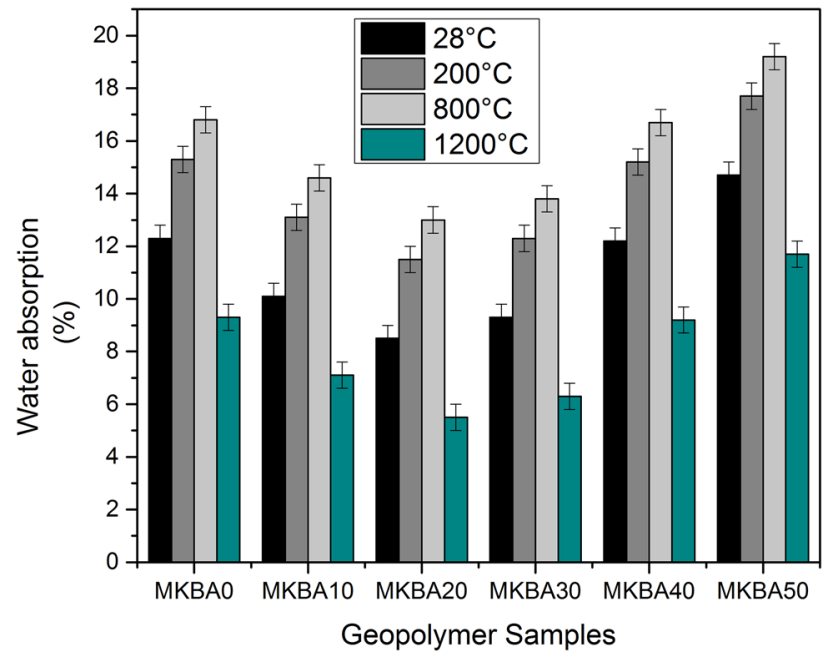

Fig. 10 Trend of the water absorption values of the geopolymer products

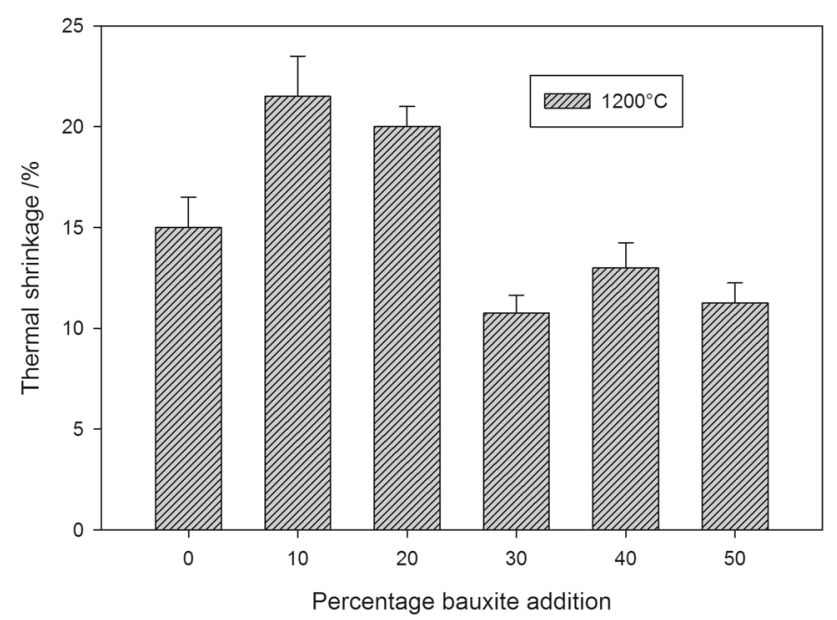

Fig. 11 Variation of the thermal shrinkage of the geopolymer samples sintered at $1200^{\circ} \mathrm{C}$

4. The thermal shrinkage was related to the physicochemical transformations that occurred within the material subjected to heat treatment. Thus, during the heat treatment of geopolymers, water removal (hygroscopic and structural) or fusion of species was observed within the matrix.

Regarding the above-mentioned results, the obtained geopolymer products could be suitable for the technological or refractory applications.

Acknowledgements The authors acknowledge the staff of the Ceramics \& Glass Laboratory of the University of Trento, Italy, for their assistance in the characterization of samples. They also recognize the assistance of MIPROMALO for the realization of this project.

\section{Compliance with ethical standards}

Conflict of interest The authors declare that they have no conflict of interest

\section{References}

1. Davidovits J (2015) Geopolymer chemistry and applications, 4th edn. Hardcover - January 1, 1809

2. Peys A, Arnout L, Blanpain B, Rahier H, Van Acker K, Pontikes $Y(2018)$ Mix-design parameters and real-life considerations in the pursuit of lower environmental impact inorganic polymers. Waste Biomass Valoriz 9:879-889. https://doi.org/10.1007/s1264 9-017-9877-1

3. Muayad E, Hubert R, Ahmed B, Hani K, Mohammed H, Jan W (2015) Development of inorganic polymer by alkali-activation of untreated kaolinitic clay: reaction stoichiometry, strength and dimensional stability. Constr Build Mater 91:251-259. https:// doi.org/10.1016/j.conbuildmat.2015.04.034

4. Yankwa Djobo JN, Elimbi A, Kouamo Tchakouté H, Kumar $\mathrm{S}$ (2016) Mechanical properties and durability of volcanic ash based geopolymer mortars. Constr Build. Mater 124:606-614. https://doi.org/10.1016/j.conbuildmat.2016.07.141

5. Provis JL, Criado M, Bernal SA, Garcia-trin P (2017) Influence of slag composition on the stability of steel in alkali-activated cementitious materials. J Mater Sci. https://doi.org/10.1007/ s10853-017-1919-3

6. Hassaan MM, Khater HM, El-mahllawy MS, El AM (2015) Production of geopolymer composites enhanced by nano-kaolin material. J Adv Ceram 4:245-252. https://doi.org/10.1007/s4014 5-015-0156-y

7. Ferone $C$, Colangelo F, Roviello $G$, Asprone $D$, Menna C, Balsamo A, Prota A, Cioffi R, Manfredi G (2013) Application-oriented chemical optimization of a metakaolin based geopolymer. Materials 6:1920-1939. https://doi.org/10.3390/ma6051920

8. Vervloet J, Van Itterbeeck P, Verbruggen S, El Kadi M, De Munck M, Wastiels J, Tysmans T (2019) Experimental investigation of the buckling behaviour of textile reinforced cement sandwich panels with varying face thickness using digital image correlation. Constr Build Mater 194:24-31. https://doi.org/10.1016/j. conbuildmat.2018.11.015

9. Łukasz K, Marcin C, Ewa K, Piotr S, Jan D, Mirja I, Łukasz G (2018) Effect of metakaolinite on properties of alkali activated slag materials. Key Eng Mater 761:69-72. https://doi.org/10.4028/ www.scientific.net/KEM.761.69

10. Parvathy S, Sharma AK, Anand KB (2019) Comparative study on synthesis and properties of geopolymer fine aggregate from fly ashes. Constr Build Mater 198:359-367. https://doi. org/10.1016/j.conbuildmat.2018.11.231

11. Shi C (2001) An overview on the activation of reactivity of natural pozzolans. Can J Civil Eng 28:778-786. https://doi. org/10.1139/cjce-28-5-778

12. Kaze CR, Tchakoute HK, Mbakop TT, Mache JR, Kamseu E, Melo UC, Leonelli C, Rahier H (2018) Synthesis and properties of inorganic polymers (geopolymers) derived from Cameroon-metahalloysite. Ceram Int 44:18499-18508. https://doi.org/10.1016/j. ceramint.2018.07.070

13. Elimbi A, Tchakoute HK, Kondoh M, Dika Manga J (2014) Thermal behavior and characteristics of fired geopolymers produced 
from local Cameroonian metakaolin. Ceram Int 40:4515-4520. https://doi.org/10.1016/j.ceramint.2013.08.126

14. Taurino R, Karamanova E, Barbieri L, Atanasova-Vladimirova S, Andreola F, Karamanov A (2017) New fired bricks based on municipal solid waste incinerator bottom ash. Waste Manag Res 35:1055-1063. https://doi.org/10.1177/0734242X17721343

15. Rashad AM (2017) Insulating and fire-resistant behaviour of metakaolin and fly ash geopolymer mortars. Proc Inst Civ Eng - Constr Mater 172:37-44. https://doi.org/10.1680/jcoma .17 .00016

16. Duxson P, Lukey GC, Van Deventer JSJ (2007) Physical evolution of Na-geopolymer derived from metakaolin up to 1000 ${ }^{\circ}$ C. J Mater Sci 42:3044-3054. https://doi.org/10.1007/s1085 3-006-0535-4

17. Kamseu E, Rizzuti A, Leonelli C, Perera D (2010) Enhanced thermal stability in $\mathrm{K}_{2} \mathrm{O}$-metakaolin-based geopolymer concretes by $\mathrm{Al}_{2} \mathrm{O}_{3}$ and $\mathrm{SiO}_{2}$ fillers addition. J Mater Sci 45:1715-1724. https ://doi.org/10.1007/s10853-009-4108-1

18. Rashad AM, Ouda AS (2018) Thermal resistance of alkaliactivated metakaolin pastes containing nano-silica particles. J. Therm Anal Calorim. https://doi.org/10.1007/s1097 3-018-7657-1

19. Martin A, Pastor JY, Palomo A, Fernández Jiménez A (2015) Mechanical behaviour at high temperature of alkali-activated aluminosilicates (geopolymers). Constr Build Mater 93:11881196. https://doi.org/10.1016/j.conbuildmat.2015.04.044

20. Dimas DD, Giannopoulou IP, Panias D (2009) Utilization of alumina red mud for synthesis of inorganic polymeric. Miner Process Extr Metall Rev. https://doi.org/10.1080/088275008024981 99

21. Kaya K, Soyer-uzun S (2016) Evolution of structural characteristics and compressive strength in red mud-metakaolin based geopolymer systems. Ceram Int. https://doi.org/10.1016/j.ceram int.2016.01.144

22. Zanelli C, Alshaaer M, Dondi M, Labrincha JA, Rocha F (2013) Composition and technological properties of geopolymers based on metakaolin and red mud. Mater Design 52:648-654. https://doi.org/10.1016/j.matdes.2013.05.058

23. Tiffo E, Batiste J, Mbah B, Désiré $P$, Belibi B, Noel J, Djobo Y, Elimbi A (2019) Physical and mechanical properties of unheated and heated kaolin based-geopolymers with partial replacement of aluminium hydroxide. Mater Chem Phys 239:122103. https:// doi.org/10.1016/j.matchemphys.2019.122103

24. Cardenia C (2019) Iron recovery from bauxite residue through reductive roasting and wet magnetic separation. J Sustain Metall 5:9-19. https://doi.org/10.1007/s40831-018-0181-5

25. Peng H, Vaughan J (2018) In-situ XRD investigation of bauxite dehydroxylation. In: Li B et al (eds) Characterization of minerals, metals, and materials 2018. TMS 2018. The Minerals, Metals \& Materials Series. Springer, Cham

26. Hertel T, Zero-waste GÁVÁ (2016) Thematic section : bauxite residue valorization a proposal for a $100 \%$ use of bauxite residue towards inorganic polymer mortar. J Sustain Metall. https://doi. org/10.1007/s40831-016-0080-6

27. Hertel T, Novais RM, Murillo R (2019) Use of modified bauxite residue-based porous inorganic polymer monoliths as adsorbents of methylene blue. J Clean Prod. https://doi.org/10.1016/j. jclepro.2019.04.084

28. Deutou JGN, Mohamed H, Nzeukou NA, Kamseu E, Melo UC, Beda T, Leonelli C (2016) The role of kyanite in the improvement in the crystallization and densification of the high strength mullite matrix: phase evolution and sintering behaviour. J Therm Anal Calorim 126:1211-1222. https://doi.org/10.1007/s1097 3-016-5686-1
29. Deutou NJG, Beda T, Biesuz M, Boubakar L, Melo UC, Kamseu E, Sglavo VM (2018) Design and characterization of porous mullite based semi-vitrified ceramics. Ceram Int 44:7939-7948. https:// doi.org/10.1016/j.ceramint.2018.01.232

30. Balo AM, Rahier H, Mobili A, Katsiki A, Fagel N, Chinje UM, Njopwouo D (2018) Metakaolin-based inorganic polymer synthesis using cotton shell ash as sole alkaline activator. Constr Build Mater 191:1011-1022. https://doi.org/10.1016/j.conbuildma t.2018.10.047

31. Kaze RC, Beleuk à Moungam LM, Fonkwe Djouka ML, Nana A, Kamseu E, Chinje Melo UF, Leonelli C (2017) The corrosion of kaolinite by iron minerals and the effects on geopolymerization. Appl Clay Sci 138:48-62. https://doi.org/10.1016/j. clay.2016.12.040

32. Tchakoute HK, Rüscher CH, Djobo JNY, Kenne BBD, Njopwouo D (2015) Influence of gibbsite and quartz in kaolin on the properties of metakaolin-based geopolymer cements. Appl Clay Sci 107:188-194. https://doi.org/10.1016/j.clay.2015.01.023

33. Duxson P, Provis JL, Lukey GC, Separovic F, Van Deventer JSJ (2005) 29Si NMR study of structural ordering in aluminosilicate geopolymer gels. Langmuir 21:3028-3036. https://doi. org/10.1021/la047336x

34. Djobo YJN, Elimbi A, Manga JD, Li IBD (2016) Partial replacement of volcanic ash by bauxite and calcined oyster shell in the synthesis of volcanic ash-based geopolymers. Constr Build Mater 113:673-681. https://doi.org/10.1016/j.conbuildma t.2016.03.104

35. Kaze CR, Djobo JNY, Nana A, Tchakoute HK, Kamseu E, Melo UC, Leonelli C, Rahier H (2018) Effect of silicate modulus on the setting, mechanical strength and microstructure of iron-rich aluminosilicate (laterite) based-geopolymer cured at room temperature. Ceram Int. https://doi.org/10.1016/j.ceramint.2018.08.205

36. Djobo JNY, Tchadjié LN, Tchakoute HK, Kenne BBD, Elimbi A, Njopwouo D (2014) Synthesis of geopolymer composites from a mixture of volcanic scoria and metakaolin. Integr Med Res. https://doi.org/10.1016/j.jascer.2014.08.003

37. Ngouloure ZNM, Nait-ali B, Zekeng S, Kamseu E, Melo UC, Smith D, Leonelli C (2015) Recycled natural wastes in metakaolin based porous geopolymers for insulating applications. J Build Eng 3:58-69. https://doi.org/10.1016/j.jobe.2015.06.006

38. Tchakouté $\mathrm{HK}$, Kamseu $\mathrm{E}$, Banenzoué $\mathrm{C}$, Rüscher $\mathrm{CH}$, Andreola $\mathrm{F}$, Tchamo CCL, Leonelli C (2018) Role of $\mathrm{y}-\mathrm{Al}_{2} \mathrm{O}_{3}$ on the mechanical and microstructural properties of metakaolin-based geopolymer cements. J Sol-Gel Sci Technol. https://doi.org/10.1007/ s10971-018-4616-z

39. Nana A, Ngouné J, Kaze RC, Boubakar L, Tchounang SK, Tchakouté HK, Kamseu E, Leonelli C (2019) Room-temperature alkaline activation of feldspathic solid solutions: development of high strength geopolymers. Constr Build Mater 195:258-268. https://doi.org/10.1016/j.conbuildmat.2018.11.068

40. Fongang RTT, Pemndje J, Lemougna PN, Melo UC, Nanseu CP, Kamseu E, Leonelli C (2015) Cleaner production of the lightweight insulating composites: microstructure, pore network and thermal conductivity. Energy Build. https://doi.org/10.1016/j. enbuild.2015.08.009

41. Kenne BBD, Elimbi A (2015) Potential of using granite waste as raw material for geopolymer synthesis. Ceram Int. https://doi. org/10.1016/j.ceramint.2015.10.091

Publisher's Note Springer Nature remains neutral with regard to jurisdictional claims in published maps and institutional affiliations. 